\title{
Remission of classic rapid cycling bipolar disorder with levothyroxine augmentation therapy in a male patient having clinical hypothyroidism
}

This article was published in the following Dove Press journal:

Neuropsychiatric Disease and Treatment

10 February 2015

Number of times this article has been viewed

\section{Pao-Huan Chen \\ Yu-Jui Huang}

Department of Psychiatry, Taipei Medical University Hospital,

Taipei, Taiwan
Correspondence: Pao-Huan Chen

Department of Psychiatry and Psychiatric

Research Center, Taipei Medical

University Hospital, \#252 Wu-Hsing

Street, Taipei, II0, Taiwan

Tel +886227372I8I ext 3666

Fax +886266315033

Email b860III5@tmu.edu.tw

\begin{abstract}
The literature suggests that patients with bipolar disorder, particularly females, have greater vulnerability to rapid cycling features. Levothyroxine therapy might be potentially useful to attenuate mood instability in this patient group. In contrast, reports on male patients remain limited and controversial. Herein, we report a 32-year-old male patient who had bipolar 1 disorder for 12 years who developed a breakthrough rapid cycling course and first-onset clinical hypothyroidism at the age of 31 years during lithium therapy. After levothyroxine augmentation therapy was introduced, the patient had remission from the rapid cycling illness course along with normalization of serum levels of free T4 and thyroid stimulating hormone in the subsequent year. This observation suggested that investigation of both levothyroxine pharmacology and thyroid pathology in male patients with rapid cycling bipolar disorder might be of much value.
\end{abstract}

Keywords: mood disorder, therapy, thyroid hormone

\section{Introduction}

According to the fifth edition of the Diagnostic and Statistical Manual of Mental Disorders (DSM-5), rapid cycling bipolar disorder is defined as the presence of at least four mood episodes within a 12-month period that meet the criteria for hypomania, mania, or a major depressive episode. ${ }^{1}$ Significantly, the prevalence rate of the rapid cycling subtype of bipolar disorder ranges from $25 \%$ to $43 \%$ in the current literature. ${ }^{2}$ Furthermore, patients with rapid cycling bipolar disorder are at an increased risk for poor treatment response, a longer course of illness, and greater morbidity and mortality. ${ }^{2}$ Nevertheless, the exact pathophysiology of rapid cycling bipolar disorder is still not clearly understood, and the current options for effective treatment remain limited.

Thyroid pathology has long been a subject of investigation in rapid cycling bipolar disorder. Evidence has indicated that levothyroxine therapy might be a potentially useful treatment to reduce mood instability in this group of patients; ${ }^{3-8}$ however, most responsive cases in the literature were females and the responses were independent of thyroid status. We present the case of a 32-year-old male who developed a breakthrough rapid cycling course and first-onset clinical hypothyroidism at the age of 31 years while receiving lithium therapy. After levothyroxine augmentation therapy was given, the patient showed significant improvement in the course of rapid cycling and abnormal thyroid function over the following year.

\section{Case report}

Mr A was a 32-year-old male patient with the first onset of a depressive episode and suicide attempt at the age of 20 years. When he was 22 years old, he had his first manic 
episode and consequently received a DSM-IV diagnosis of bipolar 1 disorder. Despite a good response to lithium $600 \mathrm{mg}$, valproic acid 1,200 $\mathrm{mg}$, and risperidone $2 \mathrm{mg}$ per day, $\mathrm{Mr} \mathrm{A}$ did not take medication regularly after each period of acute treatment. In the subsequent 5 years, he was hospitalized an average of two times each year for the acute treatment of manic or depressive episodes. During depressive episodes, therapy of lithium but not antidepressant was provided. Lamotrigine was used briefly for a depressive episode at the age of 26 years and discontinued because a subsequent manic episode occurred. Thyroid function tests showed subclinical hypothyroidism (serum free T4: $1.03 \mathrm{ng} / \mathrm{dL}$, referential range: $0.7-2.3 \mathrm{ng} / \mathrm{dL}$; thyroid-stimulating hormone [TSH]: $6.36 \mu \mathrm{IU} / \mathrm{mL}$, referential range: $0.4-5.0 \mu \mathrm{IU} / \mathrm{mL}$ ) only once during acute treatment for mania with lithium $600 \mathrm{mg}$ and valproic acid 1,700 mg per day at age 28 years.

$\mathrm{Mr}$ A received the maintenance therapy of bipolar disorder in the daycare unit from the age of 28 years. After 2-year treatment with valproic acid 1,500 mg per day, lithium $600 \mathrm{mg}$ per day, and long-acting injectable risperidone $25 \mathrm{mg}$ every 2 weeks, Mr A had more regular medication adherence and remained in remission of bipolar disorder between the ages of 28 and 30 years. By the age of 30 years, lithium and risperidone were discontinued due to intolerable hand tremors. Quetiapine $400 \mathrm{mg}$ per day was subsequently combined with valproic acid 1,500 mg per day for maintenance therapy. The follow-up thyroid function test between the ages of 28 and 30 years did not show abnormalities. In addition, Mr A did not have evidence of physical diseases or substance abuse during the period of psychiatric treatment. His firstdegree family did not report any history of psychiatric or thyroid morbidities.

At age 31 years, Mr A had a breakthrough manic episode while on maintenance therapy of valproic acid 1,500 $\mathrm{mg}$ and quetiapine $400 \mathrm{mg}$ per day. Lithium $900 \mathrm{mg}$ per day was added (serum lithium level: $0.85 \mathrm{mEq} / \mathrm{L}$ ); however, a classic rapid cycling course of illness occurred over the following year (mania for 3 months, depression for 2 months, mania for 5 months, and depression) despite the combination therapy of lithium, valproic acid, and various antipsychotics at adequate dosage for sufficient duration. During each of these episodes, serum levels of free T4 and TSH were measured. The exam during the second depressive episode of the course of rapid cycling illness showed clinical hypothyroidism (serum free T4: $0.6 \mathrm{ng} / \mathrm{dL}$; TSH: $11.5 \mu \mathrm{IU} / \mathrm{mL}$ ) for the first time in his life. Investigations for anti-thyroid peroxidase antibodies and anti-thyroglobulin antibodies were negative. A thyroid sonogram revealed diffuse goiters. Because of the clinical hypothyroidism and thyroid goiters, levothyroxine $50 \mu \mathrm{g}$ per day was administrated in addition to the psychopharmacotherapeutic regimen of lithium $900 \mathrm{mg}$, lamotrigine $50 \mathrm{mg}$, and clozapine $100 \mathrm{mg}$ per day. The major depressive episode went into remission over the following 3 months. Serum levels of free T4 and TSH then returned to normal, at $1.1 \mathrm{ng} / \mathrm{dL}$ and $3.8 \mu \mathrm{IU} / \mathrm{mL}$, respectively. Mr A maintained the therapeutic regimen and remained in remission from the rapid cycling illness for the subsequent year. No intolerable adverse effect was noted.

\section{Discussion}

This 32-year-old male carried a diagnosis of bipolar 1 disorder for 12 years. A breakthrough rapid cycling course and concurrent clinical hypothyroidism first occurred in the eleventh year of his illness despite combination treatment with various mood stabilizers and antipsychotics. Levothyroxine augmentation therapy markedly attenuated the mood instability and corrected the thyroid dysfunction. This case suggested that the pathophysiology of rapid cycling bipolar illness involves thyroid dysregulation in the subgroup of patients whose bipolar mood symptoms respond well to the administration of levothyroxine.

Previous reports have suggested that more than half of the patients with refractory rapid cycling disorder were clinically responsive to levothyroxine therapy. ${ }^{3-8}$ Notably, this treatment response was independent of clinical thyroid status despite evidence from another study showing that hypothyroidism was associated with rapid cycling in bipolar disorder. ${ }^{9}$ In these reports about levothyroxine therapy for rapid cycling bipolar disorder, responsive patients were most likely to be female. On the other hand, male patients with rapid cycling bipolar disorder were under-investigated, and the efficacy of levothyroxine therapy for these cases was controversial. Bauer and Whybrow reported successful thyroxine treatment of a male patient whose bipolar rapid cycling course began and resolved after changes in thyroid status. ${ }^{5}$ Positive results of thyroxine therapy were also observed in two other male cases reported by Bauer and Whybrow and by Weeston and Constantino. ${ }^{6,7}$ Conversely, Stancer and Persad reported only a transitory response to levothyroxine treatment in two male patients with rapid cycling bipolar disorder. ${ }^{3}$ We report a male patient with classic rapid cycling bipolar disorder and coexisting thyroid pathology who responded well to levothyroxine therapy. This finding supported that understanding thyroid pathophysiology is relevant in male patients with rapid cycling bipolar disorder and levothyroxine efficacy. 
A mechanism for the association between thyroid dysfunction and rapid cycling bipolar disorder has not been fully elucidated. Early evidence suggested that hypothyroidism decreases noradrenergic turnover rates and results in hypersensitivity of the $\beta$-adrenergic receptors. This hypersensitivity, in turn, leads to a rapid switch to mania, particularly when antidepressants that block the effects of norepinephrine reuptake are coadministered. ${ }^{10,11}$ Furthermore, emerging investigations have indicated that thyroid hormones are important regulators of the periodicity of the biological clocks underlying bipolar disorder. ${ }^{12,13}$ Impairment in self-regulation of the hypothalamic-pituitarythyroid axis may therefore contribute to the pathological oscillations of the catecholamine systems in rapid cycling bipolar disorder. ${ }^{14}$

In our case, we could not totally exclude the possibility that the hypothyroidism was associated with lithium therapy. Although the hypothyroidism in our rapid cycling bipolar patient was mild, we provided levothyroxine to him since levothyroxine therapy concurrent with lithium treatment is recommended in rapid cycling bipolar cases having thyroid goiters or clinical hypothyroidism. ${ }^{15}$ The positive result in our patient supported this recommended strategy. In contrast to previous reports about lithiumrelated hypothyroidism, ${ }^{15}$ our patient was distinct in being male, aged below 50 years, and with no family history of thyroid diseases or thyroid autoantibodies. Moreover, antidepressants were not given to our patient during major depressive episodes since antidepressants might trigger rapid cycling in bipolar disorder. ${ }^{2}$ Levothyroxine augmentation therapy therefore warrants further investigation in depressed patients with rapid cycling bipolar disorder and concurrent hypothyroidism.

Emerging evidence also suggests that combined treatment with clozapine and lamotrigine might be useful for treatmentresistant rapid cycling bipolar disorder. ${ }^{16,17}$ In our patient, we provided levothyroxine augmentation therapy 1 week after the initiation of clozapine therapy and 2 weeks before the initiation of lamotrigine. Consequently, we should also consider the possibility that this remission was due to this combination. Historically, one of our patient's episodes of depression switched to mania during lamotrigine therapy when he was 26 years old. Therefore, the present treatment response might also have been due to the addition of levothyroxine rather than to the combination of clozapine and lamotrigine. However, this hypothesis cannot be examined at this point because of clinically ethical reasons.

\section{Conclusion}

Levothyroxine augmentation therapy improved mood instability and thyroid dysfunction in our male patient with rapid cycling bipolar disorder and concurrent hypothyroidism. This observation suggested that further investigation of both levothyroxine pharmacology and thyroid pathology in male patients with rapid cycling bipolar disorder is indicated.

\section{Disclosure}

The authors report no conflicts of interest in this work.

\section{References}

1. American Psychiatric Association. Diagnostic and Statistical Manual of Mental Disorders, Fifth Edition. Arlington, VA: American Psychiatric Association; 2013.

2. Carvalho AF, Dimellis D, Gonda X, Vieta E, McIntyre RS, Fountoulakis KN. Rapid cycling in bipolar disorder: a systematic review. J Clin Psychiatry. 2014;75(6):e578-e586.

3. Stancer HC, Persad E. Treatment of intractable rapid-cycling manicdepressive disorder with levothyroxine. Clinical observations. Arch Gen Psychiatry. 1982;39(3):311-312.

4. Leibow D. L-thyroxine for rapid-cycling bipolar illness. Am J Psychiatry. 1983;140(9):1255.

5. Bauer MS, Whybrow PC. The effect of changing thyroid function on cyclic affective illness in a human subject. Am J Psychiatry. 1986;143(5): 633-636.

6. Bauer MS, Whybrow PC. Rapid cycling bipolar disorder. II. Treatment of refractory rapid cycling high-dose levothyroxine: a preliminary study. Arch Gen Psychiatry. 1990;47(5):435-440.

7. Weeston TF, Constantino J. High-dose T4 for rapid-cycling bipolar disorder. J Am Acad Child Adolesc Psychiatry. 1996;35(2):131-132.

8. Extein IL. High doses of levothyroxine for refractory rapid cycling. Am J Psychiatry. 2000;157(10):1704-1705.

9. Cowdry RW, Wehr TA, Zis AP, Goodwin FK. Thyroid abnormalities associated with rapid-cycling bipolar illness. Arch Gen Psychiatry. 1983; 40(4):414-420.

10. Extein I, Potter WZ, Wehr TA, Goodwin FK. Rapid mood cycles after a noradrenergic but not a serotonergic antidepressant. Am J Psychiatry. 1979;136(12):1602-1603.

11. Whybrow PC, Prange AJ Jr. Perspectives: a hypothesis of thyroidcatecholamine-receptor interaction. Its relevance to affective illness. Arch Gen Psychiatry. 1981;38(1):106-113.

12. Amir S, Robinson B. Thyroidectomy alters the daily pattern of expression of the clock protein, PER2, in the oval nucleus of the bed nucleus of the stria terminalis and central nucleus of the amygdala in rats. Neurosci Lett. 2006;407(3):254-257.

13. Lee HJ, Son GH, Geum D. Circadian rhythm hypotheses of mixed features, antidepressant treatment resistance, and manic switching in bipolar disorder. Psychiatry Investig. 2013;10(3):225-232.

14. Sack DA, James SP, Rosenthal NE, Wehr TA. Deficient nocturnal surge of TSH secretion during sleep and sleep deprivation in rapid-cycling bipolar illness. Psychiatry Res. 1988;23(2):179-191.

15. Kibirige D, Luzinda K, Ssekitoleko R. Spectrum of lithium induced thyroid abnormalities: a current perspective. Thyroid Res. 2013;6(1):3.

16. Calabrese JR, Gajwani P. Lamotrigine and clozapine for bipolar disorder. Am J Psychiatry. 2000;157(9):1523.

17. Bastiampillai TJ, Reid CE, Dhillon R. The long-term effectiveness of clozapine and lamotrigine in a patient with treatment-resistant rapid-cycling bipolar disorder. J Psychopharmacol. 2010;24(12): 1834-1836. 


\section{Publish your work in this journal}

Neuropsychiatric Disease and Treatment is an international, peerreviewed journal of clinical therapeutics and pharmacology focusing on concise rapid reporting of clinical or pre-clinical studies on a range of neuropsychiatric and neurological disorders. This journal is indexed on PubMed Central, the 'PsycINFO' database and CAS,

and is the official journal of The International Neuropsychiatric Association (INA). The manuscript management system is completely online and includes a very quick and fair peer-review system, which is all easy to use. Visit http://www.dovepress.com/testimonials.php to read real quotes from published authors.

Submit your manuscript here: http://www.dovepress.com/neuropsychiatric-disease-and-treatment-journal 